\title{
Analysis of the maturity of the planning and production control process based on the principles of construction lean in thirty person constructors
}

\author{
Maria Luiza Abath Escorel Borges, Henrique Sérgio Rêgo de Holanda Sá Sobrinho²
}

\author{
${ }^{1,2}$ Centro Universitário de João Pessoa/PB \\ Email: mluizabath@gmail.com, henriqiue.sobrinho@unipe.br
}

Received: March $12^{\text {th }}, 2017$

Accepted: May $21^{\text {th }}, 2017$

Published: June $30^{\text {th }}, 2017$

Copyright (C2016 by authors and Institute of Technology Galileo of Amazon (ITEGAM). This work is licensed under the Creative Commons Attribution International

License (CC BY 4.0).

http://creativecommons.org/lic enses/by/4.0/ (c) (1) (3)(2) Open Actes:

\begin{abstract}
The civil construction industry has adapted management techniques from industrial sectors to its reality, in order to eliminate waste and increase the efficiency of processes. It is in this scenario that lean construction, internationally known by lean construction, a philosophy based on the toyota production system, aims to improve the management of information, materials and people in construction. In order to evaluate the degree of application of the principles of lean construction in 30 construction companies in the capital of Paraíba, a questionnaire was used as a data collection tool to identify, in percentage terms, the current performance of each company studied in relation to lean construction. The managers responsible for the companies showed through their answers that there is a concern to adopt procedures to rationalize processes and losses.
\end{abstract}

Keywords: Lean Construction, Planning, Production and Waste.

\begin{abstract}
RESUMO
A indústria da Construção Civil tem adaptado técnicas gerenciais de setores industriais para sua realidade, com o intuito de eliminar desperdícios e aumentar a eficiência dos processos. É nesse cenário que surge a Construção Enxuta, conhecida internacionalmente por Lean Construction, filosofia baseada no Sistema Toyota de Produção, que vis a melhorar o gerenciamento de informações, materiais e pessoas na construção civil. Como objetivo de avaliar o grau de aplicação dos princípios da construção enxuta em 30 construtoras da capital paraibana, foi utilizado um questionário como ferramenta de coleta de dados para identificar, em termos percentuais, o desempenho atual de cada empresa estudada em relação a Lean Construction. Os gestores responsáveis pelas empresas mostraram por meio de suas respostas que existe a preocupação em adotar procedimentos de racionalização de processos e perdas.
\end{abstract}

Palavras Chaves: Lean Construction, Planejamento, Produção e Desperdício.

\section{INTRODUÇÃO}

Nas últimas décadas, as empresas brasileiras vêmpassando por transformações na busca contínua pela competitividade. Is so se deve às dificuldades geradas pela abertura da economia ao mercado estrangeiro, quando a Associação Brasileira de Normas Técnicas (ABNT) adotou, em 1990, as normas da série ISO 9000, publicada pela International Organization for Standardization (ISO), uma 
organização internacional cujo objetivo é padronizar as normas industriais. No mesmo período, o país passava por uma crise econômica, o que causou a queda do volume de financiamentos públicos para o mercado habitacional, agravando a situação das empresas do setor. Esse quadro as estimulou ainda mais a entrarna busca por competitividade, buscando melhorias de produtividade, qualidade e flexibilidade [1].

Depois de apresentar durante vários anos crescimento significativo, o mercado da construção civil no Brasil passa novamente por um período de estagnação. Diante de um cenário marcado por retração econômica e incertezas políticas, a Construção Civil registrou queda de $7,6 \%$ em sua parcela do Produto Interno Bruto (PIB), segundo dados divulgados pelo Instituto Brasileiro de Geografia e Estatística (2016), sendo essa a queda mais acentuada desde 2003 , de $8,9 \%$. A rentabilidade do ramo já havia diminuído consideravelmente em 2014, o que fez com que o setor diminuís se suas atividades. Dessa forma, nos anos de 2014 e 2015, a Indústria da Construção Civil (ICC), representante de grande parte do PIB nacional (cerca de 11,3\% em 2013), consequentemente sendo es sencial para o desenvolvimento do país, registrou queda de aproximadamente 8,43\% (CBIC, 2016).

Em meio a uma das circunstâncias mais adversas das últimas décadas, representantes do setor da construção civil afirmam que o atual momento é de as construtoras repensarem estratégias de mercado, aproveitando para enxugarcustos e investir em planejamento e produtividade [3]. É nesse cenário que a Construção Enxuta, conhecida internacionalmente por Lean Construction, adquire notoriedade.

Partindo destas constatações, este trabalho vis a contribuir com a comunidade científica, através de uma revisão sistemática da utilização dos princípios e ferramentas da Lean Construction como estratégia de planejamento e controle para a otimização de obras da Construção Civil, bem como fazer um estudo da utilização da filosofia enxuta em construtoras de João Pessoa.

\section{REVISÃO BIBLIOGRÁFICA}

\section{II.1 DESPERDÍCIO NA CONSTRUÇÃO CIVIL}

O modelo de gestão utilizado por grande parte das construtoras é baseado em processos de conversão, que transformam insumos em produtos intermediários ou finais. Porém, essa definição de produção tem ignorado, muitas vezes, algumas atividades que compõem os fluxos físicos entre as atividades de conversão, como por exemplo, a movimentação de materiais, de pessoas e de informações. Essas atividades são caracterizadas por não agregar valor ao produto [4]. Segundo [5], estima-se que dois terços (67\%) do tempo gasto por trabalhadores em um canteiro de obras são em atividades que não agregam valor.

Derivado de técnicas do Sistema Toyota de Produção, o modelo de gestão proposto pela Lean Construction tem, como objetivo principal, estudar a relação entre atividades de conversão e de fluxo, para reduzir ou até eliminar operações que não agreguem valor para aquele processo e que resultem em perdas de tempo e produtividade.

Para [5] define o termo "perda" como sendo algo muito além do que o desperdício de materiais. É qualquer ineficiência que ocorre no uso de equipamentos, materiais, mão de obra e capital, que acarrete em maiores quantidades àquelas necessárias para construção da edificação. Ou seja, perda é uma resposta quanto à execução de atividades desnecessárias que geramcustos adicionais que não agregam valor. De acordo com [6] dividiu as perdas em sete categorias:

a) Perdas por superprodução: São aquelas que ocorrem por produção de um produto em quantidades superiores às necessárias, como, por exemplo: produção de argamassa para reboco em quantidade superior ao necessário;

b) Perdas por es pera: Está relacionada com as atividades de fluxo de materiais e trabalhadores, como por exemplo, parada no serviço por conta de falta de equipamentos ou insumos;

c) Perdas por transporte: Está as sociada ao manus eio excessivo ou inadequado de materiais e componentes devido a uma má programação de atividades ou de um layout de canteiro ineficiente, como por exemplo, estoque de material distante do ponto de utilização;

d) Perdas no processamento em si: Está associada a falta de padronização nas atividades, ineficiência no método de trabalho e mão de obra desqualificada. São exemplos: quebra manual de blocos por de meios -blocos, ras gos na alvenaria para instalações elétricas e hidráulicas;

e) Perdas nos estoques: São aquelas que decorrem de estoques excessivos, devido a programação inadequada de compra, entrega do material ou erro na orçamentação, e que podem resultar em falta de local adequado para a disposição dos mesmos. São exemplos: deterioração do cimento por armazenamento em contato com o solo e pilhas muito altas;

f) Perdas no movimento: São aquelas que decorrem da execução de movimentações desnecessárias por parte dos trabalhadores, durante a realização de suas atividades, por conta de frentes de trabalho distantes, layout inadequado do canteiro, programação de uma sequência inadequada da atividade;

g) Perdas pela elaboração de produtos defeituosos: São aquelas que resultam em retrabalho ou redução no desempenho do produto final. Surgem da falta de integração entre o projeto e a execução, das deficiências do controle do processo produtivo ou da falta de treinamento dos funcionários. São exemplos: paredes fora de esquadro, descolamento de azulejos, falha na impermeabilização, entre outras.

Observando que exis temtantos fatores que influenciamno processo de produção, a Lean Construction veio modificar o conceito tradicional de processo de produção, com a intenção de aumentar a eficiência global dos empreendimentos do setor, buscando eliminar o máximo possível de atividades como movimentação, espera e inspeção, que não agregam valor e consomem bastante tempo no processo produtivo. Esse pensamento enxuto teve início no Japão, através do Sistema Toyota de Produção [7].

\section{II.2 SISTEMA TOYOTA DE PRODUÇÃO}

Após a Segunda Guerra Mundial, Kiichiro Toyoda, fundador da Toyota Motor Company, percebeu que os americanos ainda estavam muito à frente da sua empresa no quesito produção e essa diferença de produtividade só poderia ser explicada pela existência de perdas no sistema de produção japonês.

A partir daí, começou a estruturação de um processo para mudar esse cenário. Equipes de funcionários passaram a trabalhar juntos, tentando encontrar a melhor maneira para realizar as operações necessárias, identificando e eliminando perdas. Nesse processo de melhoria contínua, chamado Kaizen, cada trabalhador 
da linha de montagem, ao contrário do sistema de produção em massa, pudesse parar a linha de produção caso algum defeito fosse detectado [8].

Para [6] diz que os trabalhadores aprenderam não só a identificar a raiz do problema, como também a sugerir a correção para que este não voltasse a acontecer, diminuindo consideravelmente o número de erros. Com isso, a prática do Kaizen resultou na redução da necessidade de retrabalho e o aumento da qualidade dos carros fabricados. Outra meta do Sistema Toyota de Produção, conhecido como Lean Production (Produção Enxuta), é reduzir os estoques finais ao trabalhar com pequenos lotes de produção e uma alta quantidade de entregas.

Diante disso tudo, o propósito maior da Lean Production é atender da melhor maneira as necessidades do cliente, fornecendo produtos e serviços da mais alta qualidade, ao mais baixo custo e no menor tempo possível. Tudo isso, garantindo um ambiente de trabalho onde segurança e moral dos trabalhadores é uma preocupação fundamental da gerência [9].

No ano de 1973, com a Crise do Petróleo, empresas no mundo inteiro enfrentaram pesados prejuízos, enquanto a Toyota continuou obtendo lucros, sendo uma das poucas a escapar dessa crise. Este fenômeno despertou a curiosidade das organizações e a Toyota ficou conhecida mundialmente [10].

\section{II.3 LEAN CONSTRUCTION}

O termo "Lean" foi inicialmente utilizado no livro "The Machine that Changed the World" (A Máquina que Mudou o Mundo), de Womack, publicado em 1990 nos Estados Unidos. Trata-se de um amplo estudo divulgado pelo MIT (Massachussetts Institute of Technology) sobre a indústria automobilística, procurando avaliar as causas do sucesso da Toyota e o que poderia ser aprendido pelas indústrias estadunidenses.

A Lean Construction é a aplicação dos conceitos e princípios da Lean Production na construção civil. Esse conceito foi inicialmente apresentado pelo pesquisador finlandês Lauri Koskela, em 1992, ao publicar o Relatório Técnico $\mathrm{n}^{\circ} .72-$ Application of the New Production Philosophy to Construction, pela Universidade de Stanford, nos Estados Unidos da América. No relatório, ele adaptou os conceitos da Lean Production para a construção civil, propondo assim, a Lean Construction, e enumerou os seguintes onze princípios para a melhoria do fluxo da nova filosofia de gestão [11]:

a) Redução de atividades que não agregam valor;

b) Aumento do valor do produto através de uma consideração sistemática dos requisitos do cliente;

c) Redução da Variabilidade;

d) Redução do Tempo de Ciclo;

e) Simplificação pela minimização do número de passos e partes;

f) Aumento da flexibilidade na execução do produto;

g) Aumento da transparência no processo;

h) Foco no controle de todo processo;

i) Introdução da Melhoria Contínua ao Processo;

j) Balanceamento da Melhoria dos fluxos com a melhoria das conversões; k) Benchmarking (aprendizado a partir das práticas adotadas em outras empresas).

Em uma revisão de seus postulados, realizada em 2000, na publicação de sua tese de doutorado, Koskela simplifica a produção enxuta, enunciando apenas três grandes princípios. Segundo ele, ser Lean é focar em transformação, fluxo e valor.

Focar em transformação é fazer bem feito o produto, cuidar da qualidade na sua execução e aplicar da melhor maneira o esforço produtivo de máquinas e operários. Focar em fluxo é não deixá-lo parar, garantindo a sua continuidade por alguma sistemática de planejamento da produção, idealmente aquelas que determinam que um produto só deva ser produzido se ele é requerido.

Por fim, focar no valor é admitir a relevância do cliente no processo produtivo. A transformação e o fluxo só adquiremsentido se atenderemaos requisitos daqueles que vão usufruir dos bens ou serviços as sim produzidos [1].

\section{PROCEDIMENTOS METODOLÓGICOS}

Com a finalidade de atingir os objetivos definidos neste estudo, o método de pesquisa utilizado foi desenvolvido sob dois enfoques. Primeiramente foram selecionadas fontes bibliográficas para a realização da referencial teórico abordando toda a filosofia Lean, desde a sua origem no Sistema Toyota de Produção até os dias atuais, bem como o cenário da construção civil no Brasil.

Posteriormente, foi elaborado um questionário na pesquisa de campo, o qual possuía três perguntas para cada umdos onze princípios da Lean Construction, além de perguntas questionando o nível de conhecimento do próprio entrevistado em relação ao as sunto, o seu interes se em aplicar a filosofia, se acredita que a sua utilização pode melhorar o desempenho de uma obra e os possíveis obstáculos para uma empresa não querer utilizá-la. No total, foram quarenta e cinco perguntas por questionário aplicado.

$\mathrm{O}$ estudo se desenvolveu em trinta construtoras de edificações verticais localizadas na cidade de João Pessoa, todas presentes na lista do Sindicato da Indústria da Construção Civil de João Pessoa (SINDUSCON-JP), a fim de verificar, se as mesmas utilizam ou não a filosofia Lean em seus processos.

Os meios utilizados para coletar os dados necessários à pesquisa foram entrevistas acompanhadas do questionário semiaberto. Os entrevistados foram profissionais ligados ao gerenciamento de obras.

\section{RESULTADOS}

Inicialmente buscou-se determinar como os próprios entrevistados classificavam o seu conhecimento a respeito da filos ofia Lean Construction. A resposta poderia ser dada em cinco níveis, enumerados de zero a quatro, equivalendo, nessa ordem à nenhum, pouco, médio, bom e ótimo. O resultado desse quesito está exposto na Tabela 1. 
Tabela 1: Conhecimento a respeito da Lean Construction.

\begin{tabular}{ccc}
\hline Conhecimento & Frequência & Porcentual (\%) \\
\hline Nenhum & 0 & 0 \\
Pouco & 9 & 30 \\
Razoável & 13 & 43,3 \\
Bom & 8 & 26,7 \\
Muito bom & 0 & 0 \\
\hline Total & $\mathbf{3 0}$ & $\mathbf{1 0 0}$ \\
\hline
\end{tabular}

Fonte: Autores (2016).

Como pode ser visualizado, todos os entrevistados alegaram possuir algum conhecimento a respeito da Lean Construction. Quase metade deles disseram que têm um entendimento razoável, totalizando $43,3 \%$. Apenas oito pessoas responderam como tendo bom, e nove pensam saber pouco da filosofia enxuta.

Em relação ao conhecimento, foi feita outra análise utilizando a mediana do desempenho das empresas. Foi calculada a mediana de cem pontos. Como no total são trinta empresas, is so quer dizer que quinze empresas pontuaram acima de cem, e quinze abaixo de cem, já que a mediana é o valor que divide a amostra em duas partes iguais. A Tabela 2 mostra a distribuição das empresas de acordo com o conhecimento declaro, relacionando com as suas respectivas pontuações.

Tabela 2: Relação do conhecimento declarado com a pontuação obtida.

\begin{tabular}{cccccc}
\hline Mediana & Nenhum & Pouco & Razoável & Bom & Ótimo \\
\hline Abaixo de 100 & 0 & 6 & 6 & 3 & 0 \\
Acima de 100 & 0 & 3 & 7 & 5 & 0 \\
\hline Total & $\mathbf{0}$ & $\mathbf{9}$ & $\mathbf{1 3}$ & $\mathbf{8}$ & $\mathbf{0}$ \\
\hline
\end{tabular}

Fonte: Autores (2016).

Uma contradição observada é que das oito que responderam o questionário como tendo bom conhecimento em torno da construção enxuta, três empresas adquiriram pontuação abaixo da mediana. Ou seja, mesmo sabendo que a utilização da Lean Construction como modelo de gestão aumenta a eficiência global do empreendimento, a aplicação não acontece nas suas obras. Por isso, é preciso saber quais fatores impedem a prática Lean nessas construtoras. A Tabela 3 apresenta as res postas que os engenheiros deram para o principal entrave que impedem as construtoras, de uma maneira geral, não se utilizar essa metodologia de gestão.

Tabela 3: Principais entraves para a implantação da Lean Construction.

\begin{tabular}{|c|c|c|}
\hline Entraves & Frequência & Porcentual (\%) \\
\hline $\begin{array}{c}\text { Custos de implantação (gastos com consultorias e } \\
\text { treinamentos) }\end{array}$ & 9 & 30 \\
\hline $\begin{array}{l}\text { Dificuldade dos funcionários em compreenderem a } \\
\text { filosofia }\end{array}$ & 7 & 23,3 \\
\hline Não confiar na expectativa de bons resultados & 3 & 10 \\
\hline $\begin{array}{l}\text { Não ser uma filosofia com técnicas disseminadas na } \\
\text { região }\end{array}$ & 11 & 36,7 \\
\hline Total & 30 & 100 \\
\hline
\end{tabular}

Fonte: Autores (2016). 
A última opção foi a mais votada, com $36,7 \%$, que é onde entra a questão da cultura. As empresas têm medo ou receio de inovar e não dar certo, acarretando em prejuízo. Apesar disso, apenas três empresas não confiam em bons resultados aplicando a Lean Construction. Do restante, nove apontaram os custos de implantação como principal entrave e sete indicaram a dificuldade em compreender a filosofia. Para esse, existem consultorias especializadas em construção enxuta, atuando em conjunto comos fornecedores do setor da construção civil, revendo processos e métodos, afim de utilizar um melhor gerenciamento da obra.

Após apresentar toda a teoria da metodologia enxuta na construção, o questionário buscou também saber o interesse em aplicar esse modelo de gestão nas obras em questão. O quesito tinha cinco opões de resposta: nenhum, pouco, razoável, bom e ótimo. O resultado é apresentado na Tabela 4:

Tabela 4: Interesse em aplicar a Lean Construction.

\begin{tabular}{ccc}
\hline Interesse & Frequência & Porcentual (\%) \\
\hline Nenhum & 0 & 0 \\
Pouco & 1 & 3,3 \\
Razoável & 4 & 13,3 \\
Bom & 16 & 53,3 \\
Ótimo & 9 & 30 \\
\hline Total & 30 & 100 \\
\hline
\end{tabular}

Fonte: Autores (2016).

Ninguém disse não ter interesse, mas uma pessoa tem pouco, e quarto, razoável. Como já era esperado, a maior parte tem de bom a ótimo nível de interesse, representando vinte e cinco empresas, ou $83,3 \%$ do total. Is so mostra que a maior parte delas acredita nos benefícios desse modelo de gestão.

Partindo para a análise das perguntas relacionadas aos princípios da Lean Construction, todos eles possuíampesos iguais, ou seja, o mesmo nível de importância. Sabendo que eram onze princípios, que cada um possuía três perguntas, que cada pergunta possuía cinco níveis de respostas ( 1 - nunca, 2 - quase nunca, 3 - às vezes, 4 - quase sempre, 5 - sempre), conclui-se que a pontuação máxima possível é de cento e sessenta e cinco pontos. Dividindo o somatório dos pontos de cada empresa por esse valor total, foi determinada a média do desempenho individual das mesmas. $\mathrm{O}$ resultado é mostrado na Tabela 5 .

Tabela 5: Pontuação das empresas.

\begin{tabular}{cccccc}
\hline Empresa & Pontuação & Média (\%) & Empresa & Pontuação & Média (\%) \\
\hline 1 & 111 & 67,27 & 16 & 109 & 66,06 \\
2 & 104 & 63,03 & 17 & 77 & 46,67 \\
3 & 97 & 58,79 & 18 & 112 & 67,88 \\
4 & 127 & 76,97 & 19 & 102 & 61,82 \\
5 & 63 & 38,18 & 20 & 104 & 63,03 \\
6 & 98 & 59,39 & 21 & 108 & 65,45 \\
7 & 95 & 57,58 & 22 & 103 & 62,42 \\
8 & 93 & 56,36 & 23 & 115 & 69,70 \\
9 & 111 & 67,27 & 24 & 91 & 55,15 \\
10 & 115 & 69,70 & 25 & 71 & 43,03 \\
11 & 84 & 50,91 & 26 & 105 & 63,64 \\
12 & 102 & 61,82 & 27 & 86 & 52,12 \\
13 & 82 & 49,70 & 28 & 96 & 58,18 \\
14 & 87 & 52,73 & 29 & 63 & 38,18 \\
15 & 103 & 62,42 & 30 & 70 & 42,42 \\
\hline
\end{tabular}

Fonte: Autores (2016).

Somando todas as pontuações e dividindo pelo número de construtoras, obteve-se a média geral de 96,1 pontos, que corresponde a $58,24 \%$ do total. Ou seja, pode-se dizer que cerca de $60 \%$ da filos ofia enxuta é presente nas construtoras da cidade de
João Pessoa, mesmo que inconscientemente. Os gestores responsáveis pelas empresas mostrarampor meio de suas res postas que são adotados procedimentos de racionalização de processos e perdas. 
As empresas que consideram adotar a Lean Construction não aplicam totalmente os princípios da filosofia. Talvez isso aconteça porque alguns deles são considerados menos importantes que outros, recebendo assim, menos atenção. Com a intenção de fazer a análise disso, a Tabela 6 ilustra a média individual deles, juntamente com os seus respectivos desvios padrões, bem como a média e desvio padrão geral.

Tabela 6: Resultados dos princípios da Lean Construction.

\begin{tabular}{cc}
\hline Princípios & Média \\
\hline Redução de atividades que não agregam valor & 9,5 \\
Aumento do valor do produto através de uma consideração sistemática dos & 8,1 \\
requisitos do cliente & Redução da variabilidade \\
Redução do tempo de ciclo & 10,13 \\
Simplificação pela minimização do número de passos & 7,8 \\
Aumento da flexibilidade na execução do produto & 8,9 \\
Aumento da transparência no processo & 8,07 \\
Foco no controle do processo global & 9,07 \\
Introdução da melhoria continua no processo & 9,93 \\
Balanceamento da melhoria dos fluxos com a melhoria das conversões & 8,3 \\
Benchmarking & 8,77 \\
\hline Desempenho geral & 7,53 \\
\hline
\end{tabular}

Fonte: Autores (2016).

O princípio com maior média é o de reduzir a variabilidade. Do ponto de vista da construção enxuta, a variabilidade pode ser nos processos anteriores, relacionada aos fornecedores do processo; no próprio processo, relacionada à execução de alguma atividade; ou na demanda, relacionada aos desejos e necessidades dos clientes. É importante tentar simplificar ao máximo, pois a variabilidade tende a aumentar a parcela de atividades que não agregam valor e o tempo necessário para executar um produto.

A prática do benchmarking, princípio com média mais baixa, possibilita reconhecer que outra empresa pode executar um processo de maneira mais eficaz, para que possam ser adaptados à própria empresa. É fundamental fazer esse processo, para que a forma de gerenciamento e controle da produção da própria empresa possa ser otimizada. Uma das perguntas do questionário questionava diretamente se as empresas procuram técnicas de sucesso em outras e consideram como um modelo a ser espelhado. Para essa pergunta, quase metade das empresas responderam que nunca fazem isso, o que deixa a entender que elas consideram a metodologia própria tão eficiente que não precisa ser melhorada.

As outras fazem uso de modelos bem-sucedidos como referências na execução da obra, porém, não com máxima consistência possível.
Ainda foi feita uma correlação entre pontuação obtida e o tempo de atuação da empresa no mercado, com o intuito de descobrir se há relação entre os dois parâmetros. O tempo médio de empresa é de 14,4 anos e como já foi visto, a pontuação média é de 96,1 pontos.

A correlação avalia diretamente o grau de relacionamento entre duas variáveis distintas. Para o presente trabalho foi utilizada a Correlação de Pearson, um coeficiente que quantifica a força de as sociação linear entre X e Y, descrevendo o quão bem uma linha reta se ajusta através de pontos no plano cartesiano.

Se os pontos ficam localizados exatamente sobre uma linha crescente então " $r=1$ ", e se ficam localizados exatamente sobre uma linha decrescente, " $r=-1$ ". Quanto mais perto de um, independente do sinal, maior é o grau de dependência estatística linear entre as variáveis. Por outro lado, quanto mais próximo de zero for o valor, menor será a força dessa relação. O coeficiente tem um caráter adimensional, ou seja, ele é desprovido de unidade física que o defina. Não faz sentido interpretar uma correlação de 0,3 como sendo 30\%, por exemplo (BISQUERA, 2004). Na presente correlação, o tempo está representando o valor de X, em anos, e o desempenho o lugar de Y, em pontos. O software IBM SPSS Statistics fez o cálculo e gerou o resultado apresentado na Tabela 7.

Tabela 7: Correlação de Pearson entre tempo e desempenho.

\begin{tabular}{ccc}
\hline Variáveis & Tempo & Desempenho \\
\hline Tempo & 1 & $0,571^{* *}$ \\
Desempenho & $0,571^{* *}$ & 1 \\
\hline
\end{tabular}

Fonte: Autores (2016).

A relação entre tempo e desempenho é de $0,571^{* *}$, valor que classifica a correlação como sendo moderada positiva. Os dois asteriscos após o coeficiente expressam que a correlação é significativa no nível 0,01 . Portanto, o software alegou que a hipótese nula, de que esse resultado aconteceu por acaso, é falsa e existe $99 \%$ de chance de acerto no Coeficiente de Pearson obtido pelo software. A correlação moderada positiva de 0,571 entre a média do tempo de atuação de cada empresa declarado na Receita Federal e o desempenho das mesmas em relação à utilização da Lean Construction é uma similaridade real e não acontece por acaso. 


\section{CONSIDERAÇÕES FINAIS}

As respostas dadas pelos entrevistados indicam que a filosofia ainda é pouco disseminada na região. Os que afirmaram ter um bom nível de conhecimento a respeito do assunto, disseram que apenas lerame estudaram sobre. Deste modo, perguntas mais minuciosas são necessárias para que se possa obter uma resposta que esteja de acordo com a realidade, pois, não seria adequado atribuir o mesmo nível de conhecimento para alguém que estudou a filosofia e outro que tenha trabalhado com ela.

Também pode-se chegar à conclusão de que todos os entrevistados possuem interesse em aplicar a construção enxuta, mesmo que mínimo, e acreditam que sua utilização pode melhorar o desempenho de suas empresas. Is so leva a crer que existe espaço na construção civil para a implementação da filosofia. Porém, esse resultado entra em contradição com relação aos obstáculos enfrentados para essa implementação, pois as empresas alegaramo fato de não ser uma técnica muito difundida na região como o principal entrave. Assim, deve-se fazer conhecidos os conceitos e vantagens da aplicação do pensamento enxuto para todos os envolvidos na construção civil da cidade.

Em relação a aplicação dos princípios, nota-se uma variação na relevância que as empresas dão para cada um, mas reduzir a variabilidade e focar no controle do processo global possuem maior relevância no quadro geral. Além disso, atender as considerações feitas pelos clientes é de comum importância para todas. Logo, é perceptível o valor desse princípio no dia-a-dia das construtoras, pois entender as necessidades dos clientes é característica primordial para a permanência no competitivo mercado da construção.

Diante disso, pode-se afirmar que o objetivo desse trabalho foi alcançado ao identificar o nível de aplicação da Lean Construction e o desempenho global de cada construtora, e concluir, que existe a preocupação nas empresas emotimizar seus proces sos produtiv os e reduzir os desperdícios.

\section{REFERÊNCIAS}

[1] Heineck, Luiz et al. Logística e Lógica na Lean Construction: Um Processo de Gestão Transparente na Construção de Edifícios. Fortaleza: Fibra Construções Ltda, 2004. 152f.

[2] Câmara Brasileira da Indústria da Construção - CBIC. 2016.

[3] Leão, Cintia Loturco Pinheiro. Estimativa da correção do coeficiente de retorno de esgoto sanitário em habitações com sistemas de aproveitamento de água pluvial: estudo de caso da cidade de Bauru (SP). Dissertação de Mestrado da Universidade Estadual Julio de Mesquita Filho (UNESP). 2015.

[4] Rezende, Juliana S. et al. Identificação das práticas da filosofia Lean Construtoras de médio porte na cidade de Itabuna (BA), Engevista, V.14, dez. 2012.

[5] Formoso, Carlos T. et al. As perdas na construção civil: conceitos, classificações e seu papel na melhoria do setor. 1996.

[6] Shingo, Shingeo; Sistemas de Produção com Estoque Zero: o Sistema Shingo para melhorias contínuas. Porto Alegre: Bookman Companhia Editora, 1996.
[7] Paixão, L. G. A.; Implementação de práticas da produção enxuta: um estudo de caso em uma fábrica de produtos de papel. 2011. 119p. Monografia (Graduação em Engenharia de Produção) - Universidade de São Paulo. 2011.

[8] Picchi, F. A.; Lean Thinking (Mentalidade Enxuta): Avaliação Sistemática do Potencial de Aplicação no Setor de Construção. In: Simpósio Brasileiro de Gestão da Qualidade e Organização do Trabalho no Ambiente Construído. 2001. Artigo técnico, Fortaleza.

[9] Womack, James P., Mentalidade Enxuta nas Empresas: elimine os Desperdícios e Crie Riqueza. 7. ed. Ed. Rio de Janeiro: Campus, 2004.

[10] Ghinato, Paulo et. al. Um modelo para o sistema de construção enxuta a partir do Sistema Toyota de Produção. XXIII Encontro Nac. de Eng. de Produção - Ouro Preto, MG, Brasil, 21 a 24 de out de 2003.

[11] Denari, Caio G. Aplicação dos princípios da construção enxuta em empresas construtoras. 2010. 67f. Monografia (Graduação em Engenharia Civil) - Universidade Federal de São Carlos. 2010. 